\title{
Epigenetic regulation in lymphoma
}

\author{
Saeeda Khanum ${ }^{*}$, Hayat Ullah' ${ }^{2}$ Jamila Shuja ${ }^{3}$, Muhammad Hashim \\ Jan $^{1}$, Muhammad Sharif Jamali ${ }^{1}$, Iqra Arshad ${ }^{1}$, Shamsuddin ${ }^{4}$, Samreen \\ Shabir ${ }^{1}$ and Amna Bano ${ }^{5}$
}

1. Institute of Biochemistry, University of Balochistan Quetta, 87300-Pakistan

2. Department of Oncology, Bolan Medical Complex (BMC) Quetta-Pakistan

3. Center for Nuclear medicine and Radiotherapy (CENAR) Quetta-Pakistan

4. Peer Abdul Qadir Shah Jelani Institute of Medical Sciences Ghambat Sindh-Pakistan

5. Department of Chemistry, University of Balochistan Quetta-Pakistan

*Corresponding author's email: saeedakhanum4@gmail.com

\section{Citation}

SaeedaKhanum, Hayat Ullah, Jamila Shuja, Muhammad Hashim Jan, Muhammad Sharif Jamali, Iqra Arshad, Shamsuddin, SamreenShabir and AmnaBano. Epigenetic regulation in lymphoma. Pure and Applied Biology. Vol. 9, Issue 1, pp448-454. http://dx.doi.org/10.19045/bspab.2020.90049

\begin{tabular}{llll}
\hline \hline Received: 28/08/2019 & Revised: 25/10/2019 & Accepted: 01/11/2019 & Online First: 13/11/2019 \\
\hline \hline
\end{tabular}

\section{Abstract}

Epigenetic mechanisms are essential for normal growth and development for the preservation of gene expression patterns in mammalian specific tissues. Global changes in the epigenetic land scape are a sign of cancer. Cancer is considered as one of the genetic diseases, but it has recently become clear that epigenetic alterations have been implicated in the progression and initiation of cancer. Recent advances in the rapidly evolving field of epigenetic cancer have revealed a general reprogramming of all components of epigenetic cancer machines, such as histone modifications, DNA methylation and non-coding RNAs, in particular microRNA expression as well as the positioning of the nucleosome. The reversible nature of epigenetic aberrations has led to the manifestation of potential exposures of epigenetic therapy that is improving with the current FDA approval for some epigenetic drugs for cancer treatment. In B cell lymphomas, epigenetic mutations and perturbations of the epigenetic structure are recent events. The main objective of this review is to highlight some important discoveries involved in epigenetic regulation and to provide a theoretical framework to examine them that how epigenetic modifications could contribute to lymphomagenesis.

Keywords: CHOP; DNA methylation; Epigenetic; EP300/ CREBBP; EZH2; HDAC; Histone acetyltransferase

\section{Introduction}

Epigenetic is defined as the interaction of gene with its environment that gives rise to the phenotype. It is defined as a bridge between phenotype and genotype and can be associated with many exogenous factors, such as some environmental factors that alter the bridge between the environment and the genome [1, 2]. Epigenetic is a branch of biology linked to the study of occasional connections between a gene and its phenotypic products [3]. But epigenetic is a recent reference to changes in phenotypic variables. These hereditary alterations are reversible and independent of DNA sequences [1, 4]. In 1957, Waddington proposed a cell theory according to which the multicellular organisms would have the same genotype but in the whole cellular segregation a different phenotype would be 
created. In addition, to distinct models of gene expression and cellular function [5]. In mammals antigenic changes are involved in the expression and development of the specific tissue gene. The interruption of epigenetic processes is implicated in cellular neoplasms and in the altered gene function. Furthermore, epigenetics plays a fundamental role in the biology of enormous arrangements during normal stages of development and growth [6, 7]. In the mammalian genome, epigenetics is linked to the large number of retroviral and transposable elements [8, 9]. Epigenetic aberrations are at the origin of many pathologies such as certain immune system disorders, nervous system disorders, tumors and endocrine disorders [10-13]. In the process of tumor genesis epigenetic alterations function as an alternative to mutations. Recently, it has been established that the modification of epigenetic is very important for the initiation process and for progression [14].

During the differentiation, many hereditary changes occur while during multiple cycles of cell division these changes are stable allowing cells to have different identities despite having the same genetic information. Epigenetic modifications are implicated in the types of gene expression patterns such as post translation modification of histone proteins in DNA, and in cytosine-based methylation position of nucleosomes in DNA [15]. Collectively, the compliments of these changes refer to the epigenome and this provides a mechanism for cellular multiplicity by variable and by cellular mechanism, that what kind of genetic information can be accessed. Due to the failure in the correct preservation of hereditary, epigenetic traits that result in an activation or inappropriate initiation of a variety of signaling pathways and leading to a disease such as cancer $[16,17]$. In many recent studies, it has been revealed that human cancer cells anchor epigenetic irregularities and genetic transformation around the world [17, 18]. During the development of cancer cells, these genetic and epigenetic alterations work together. The genetic origin of cancer is widely conventional and in many types of cancer the epigenetic alterations are considered of the initiation factor. These recent discoveries have allowed us to understand the role of epigenetics, which causes cancer. Epigenetic abnormalities similar to mutations are probably unpredictable from epigenetic therapy. These genetic mutations can be restored to their usual position and these epigenetic therapies make these initiatives capable and therapeutically appropriate [15]. In this brief review, the researcher focused on the three main areas of epigeneticsthat have been implicated in leukemogenesis, DNA hypermethylation, histone modification, and microRNA alterations.

\section{Epigenetic mechanism of gene regulation}

In mammals various gene expressions are due to the epigenetic mechanisms necessary for the normal growth of specific-tissues. If these mechanisms are interrupted there is room for modifying the function of genes and the formation of tumor cells. The implication of the epigenetic with gene is a semi reversible covalent chemical modification of a protein with DNA bases and to which DNA is associated with the cell nucleus [19]. Epigenetic mechanism of the gene involved in histone modification, DNA methylation, non-coding RNA and gene silencing related to chromatin remodeling [20]. Some abnormally expressed genes (Table 1) that are involved in epigenetic modification during the tumor cell appearance in human [21]. 
Table 1.Some epigenetic modifier genes in human cancer

\begin{tabular}{|c|c|c|}
\hline Gene Change & Cancer & Cancer types \\
\hline AID & Increased & Leukemia \\
\hline DNMT1 and DNMT3B & Increased & $\begin{array}{c}\text { Pancreas, liver, bladder and } \\
\text { breast cancers }\end{array}$ \\
\hline EHMT1 & Decreased & Medulloblastoma \\
\hline EZH2 & Increased & Prostate and breast cancers \\
\hline HDACs & Increased & several cancers \\
\hline IGF2 & Increased & $\begin{array}{c}\text { Colorectal,gastric and breast } \\
\text { cancers }\end{array}$ \\
\hline KATs & Decreased & several cancers \\
\hline KDM5C & Increased & Breast cancer \\
\hline SIRT1 and SIRT3 & Increased & Prostate and breast cancers \\
\hline SMYD3 & Increased & Liver, colon and breast cancers \\
\hline
\end{tabular}

AID: activation induced cytidine deaminase; DNMT: DNA methyltransferase; EHMT1: euchromatic histone lysine N-methyltransferase 1; EZH2: enhancer of zeste homologue 2; KAT: lysine acetyltransferase; HDAC, histone deacetylase; IGF2: insulin like growth factor 2; KDM5C: lysine specific demethylase 5C; SIRT:sirtuin; SMYD3: SET and MYND domain containing 3[21].

\section{Epigenetics and cancer}

Epigenetics is the study of biochemical changes in chromatin and has been implicated in the pathogenesis of cancer [22, 23]. The combination of genetic and epigenetic abnormalities causes cancer resulting in the interpretation and functioning of the dysregulated gene [24]. Some of the predominantly epigenetic changes are tested and increase the level of methylation of the $\mathrm{CpG}$ islands, the deacetylation and methylation of histone proteins and noncoding RNA [25].

\section{Epigenetic regulation in lymphoma DNA methylation}

The attachment of the methyl group to the DNA molecule is called DNA methylation. Without any change in DNA sequences, it can change DNA activity. This is the transcription of a gene when methylation takes place in a gene promoter. It involves the normal growth of mammalian cells and is also linked to other processes such as $\mathrm{X}$ chromosome activation, genomic fingerprinting, aging and carcinogenesis. In the DNA methylation process, two nitrogenous bases are methylated, cytosine and adenine. During epigenetic programming, DNA methylation is essential for normal B cell growth and interrupted during lymphomagenesis [26]. In lymphomagenesis, DNMTs play an essential role, in particular due to the overexpression of $48 \%, 13 \%$ and $45 \%$ of DLBCL 81 and are associated with the achievement of advanced clinical stages. Furthermore, DNMT3b and DNMT1 coordinate with processing resistances while DNMT3b overexpression is involved in free progression. Guan et al, KLF4 has been reported as an abnormally hypermethylated tumor suppressor gene in many lymphoma subtypes, including FL, DLBCL, Burkitt's lymphoma (BL) and classic Hodgkin's lymphoma (HL), suggesting independent mechanisms common to lymphomagenesis [27]. Furthermore, in mature aggressive B-cell NHL, the study of approximately 85 cases in all lymphoma subtypes is due to the de novo methylation of 56 genes and 22 genes with specific methylation [28]. Recently, it has also been reported that the MCL methylation profile showed 252 hypermethylated genes that are involved in the high level of chromosomal abnormalities, increased proliferation and shorter survival of patients. 


\section{Histone modification}

Histones are composed of about 30 small chains of amino acids. Histone tails are involved in various post-translational modifications and therefore form histone codes. These changes are involved in gene expression, DNA damage / repair, regulation of chromatin function and DNA replication. In histone residues, arginine and lysine are the most important modification sites. Furthermore, acetylation and methylation are common functions of the side chain amino acids. In the regulation of epigenetics, different histone modifications are involved and play an important role in methylation and acylation, while in the regulation of epigenetics several histone modifications are involved which play an important role. In methylation and acetylation that are medically related to pathological epigenetic destruction in many tumors such as in lymphoma the loss of the exact residue in acetylation and methylation in the central histones $\mathrm{H} 4$ and $\mathrm{H} 3$ are determined as markers of tumor cells [29]. In the acetylation process of $\mathrm{H} 4$ and $\mathrm{H} 3$, the situation is mainly related to the association of chromatin, gene expression and transcription from the opposite activity of HDAC and HAT as a result the acetylation process takes place. There are three main families of HAT groups that transfer acetyl groups to histone lysine nucleosome residues: families CBP / P300, SAS2 / MOZ / TIP60 / YBF2 (MYST) and GCN5 N-acetyltransferase [30]. In the transcription process, HATs are selected as co-activators by the transcription factor. PCAT methylated PCAF proteins such as CBP, EP300 and these HATs play an important role in lymphoma progression [3133]. EP300 and CREBBP are highly conserved and widely distributed enzymes belonging to the KAT3 acetyltransferase family that are involved in the interaction of about 400 to 450 proteins [34]. Furthermore, the loss of CBP facilitates the development of lymphomas derived from the germinal center (GC) in mice. It is interesting to note that this has been suggested to depend on an epigenetic landscape disturbed in these cells, since the loss of CBP results in uncontrolled deacetylation at the activators of B-cell signaling genes and of the immune response [35]. CBP and EP300 activate transcription by histone acetylation or by regulation of transcription factor activity by direct interaction or acetylation [36]. Another HAT called TIP60 plays a significant role in the progression of tumorigenesis involving the modulation of signaling events that occur in the TMJ like DNA thus damaging the activation of MYC and P53 that is regulated in transcription [37].

\section{Noncoding RNA/miRNA}

The miRNAs are actually small non-coding RNA molecules composed of about 22 nucleotides. The miRNAs in post-translation modification are involved in gene expression, regardless of whether their translation is inhibited or targeted. In 2000, human miRNAs are discovered. The miRNAs are involved in various human diseases such as miRNA15 and miRNA16-1 LLC repression involved in the progression of tumorgenesis, mainly in lymphoma [38]. It is clear that, gene silencing in miRNAs results in a deregulation of treatment machines, epigenetic alterations and genomic changes, involved in the progression of oncogenesis (oncomiR). First, the discovered oncoms are miR155 and miR17-92 both involved in lymphoma progression. Overexpression is involved in miR17-92 B-cell lymphoma. And these neoplasms are due to the cluster target gene such as E2F, CDK1A, PTEN, and BIM that increased proliferations [39]. In the deregulation of miR17-92, the MLL proteins are targeted and these MLL protein are arranged. Another example of miR155 is involved in B cell expansion leading to lymphoma amplification leading to lymphoma amplification [40]. Activation of 
NF-kB results from TNFAIP3 targets onvomiR $125 \mathrm{a}$ and $\mathrm{miR} 125 \mathrm{~b}$. In the tumor suppressor LLC miR15a / 16-1, targets BCL2. Another example of epigenetic neutralization of miRNAs is in the repression of NHR and LLC of miR296, miR16 and miR15a by HDAC complexes [41].

\section{Conclusion}

Epigenetic and transcriptional modifiers are affected by mutations and appear to be globally characteristic of B-cell lymphomas. Furthermore, large-scale destruction of DNA methylation and changes in many models, such as histone, are promising. It is an indication of diseases like cancer that has also been the basis for targeted epigenetic therapy. Next-generation therapeutic approaches for individualization and sequencing can generate unique expression patterns, leading to a specific molecular phenotype. The challenges that have been faced for many years, are due to the epigenome of lymphoma and some biological and biochemical effects of the epigenetic factors of these mutants just as it is very imperative to determine the methylation count of DNA classifiers as a biomarker by considering therapeutic stratifications and distinguishing accuracy. Probably, these epigenetic impressions are reversible. Moreover, the growth of authentic drugs that deals with the epigenetic modifications that cause mutations have kept the carelessness. Previously, promising agents that treat the chromatin-modifying enzyme and target proteins as well as an epigenetic reader and a transcription factor like some long-term agents, could develop considerably in the treatment of B-cell lymphoma. In the immune system and in other parts of the body, these promising drugs are responsible for reducing toxins. Future and ongoing studies are currently evaluating various combinations of mutually epigenetic therapies as well as fusion with conventional chemotherapeutic agents.

\section{Authors' contributions}

Conceived and designed the experiments: $S$ Khanum, Wrote the paper: $\mathrm{S}$ Khanum, $\mathrm{H}$ Ullah, J Shuja, MH Jan, MS Jamali, I Arshad, Shamsuddin, S Shabbir \& A Bano.

\section{References}

1. Loscalzo J, Handy DE \& Castro R (2011). Epigenetic modifications: basic mechanisms and role in cardiovascular disease. Circulation 123(19): 21452156.

2. Fraga MF, Ballestar E, Paz MF, Ropero S, Setien F, Ballestar ML \& BoixChornet M (2005). Epigenetic differences arise during the lifetime of monozygotic twins.Proc Natl Acad Sci102(30): 10604-10609.

3. Waddington $\mathrm{CH}$ (2011). The epigenotype. Int J Epidemiol 41(1): 1013.

4. Berger SL, Kouzarides T, Shiekhattar R \& Shilatifard A (2009). An operational definition of epigenetics. Genes Dev 23(7): 781-783.

5. Waddington $\mathrm{CH}$ (2014). The strategy of the genes. $1^{\text {st } E D . R o u t l e d g e ; ~ N e w ~ Y o r k . ~}$

6. Hore TA, Rapkins RW \& Graves JAM (2007). Construction and evolution of imprinted loci in mammals. Trends Genet 23(9):440-448.

7. Yen ZC, Meyer IM, Karalic S \& Brown CJ (2007). A cross-species comparison of X-chromosome inactivation in Eutheria. Genomics 90(4): 453-463.

8. Bird A (1997). Does DNA methylation control transposition of selfish elements in the germline? Trends Genet 13(12): 469-470.

9. Yoder JA, Walsh CP \& Bestor TH (1997). Cytosine methylation and the ecology of intragenomic parasites. Trends Genet 13(8):335-340.

10. Gos M (2013). Epigenetic mechanisms of gene expression regulation in 
neurological diseases. Acta Neuro boil $\operatorname{Exp}$ 73: 19-37.

11. $\mathrm{Yu} \mathrm{DH}$, Waterland RA, Zhang $\mathrm{P}$, Schady D, Chen MH, Guan Y \& Shen L (2014). Targeted p16 Ink4a epimutation causes tumorigenesis and reduces survival in mice. Eur $J$ Clin Invest 124(9):3708-3712.

12. GRØNBÆK K, Hother C \& Jones PA (2007). Epigenetic changes in cancer. Apmis 115(10): 1039-1059.

13. Zhang X \& Ho SM (2011). Epigenetics meets endocrinology. $J \quad \mathrm{Mol}$ Endocrinol 46(1): R11-R32.

14. Feinberg AP, Ohlsson R \& Henikoff $S$ (2006). The epigenetic progenitor origin of human cancer. 14 Nat Rev Genet 7(1): 21.

15. Sharma S, Kelly TK \& Jones PA (2010). Epigenetics in cance. Carcinogenesis 31(r1): 27-36.

16. Egger G, Liang G, Aparicio A \& Jones PA (2004). Epigenetics in human disease and prospects for epigenetic therapy. Nature 429(6990): 457.

17. Jones PA, \& Baylin SB (2002). The fundamental role of epigenetic events in cancer. Nat Rev Genet 3(6): 415.

18. Jones PA \& Baylin SB (2007). The epigenomics of cancer. Cell 128(4): 683-692.

19. Armstrong L (2013). Introduction to the study of epigenetics, In: UK: Garland Science. DNA Methylation Socpp 300.

20. Unterberger A, Andrews SD, Weaver IC $\& \quad$ Szyf M (2006). DNA methyltransferase 1 Knockdown activates a replication stress checkpoint. Mol Cell Biol 26(20): 75757586.

21. Nawaz I (2015). Employing epigenetic marks to detect cancer: studies on nasopharyngeal carcinoma and lung cancer, Ph.D Thesis. Deptt. Of Microbiology Tumor \& Cell Biology. Karolinska. Inst., Stockolm, Sweden.
22. Sandoval J \& Esteller M (2012). Cancer epigenomics: beyond genomics. CurrOpin Genet Dev 22(1): 50-55.

23. You JS \& Jones PA (2012). Cancer genetics and epigenetics: two sides of the same coin? Cancer Cell Int 22(1): 9-20.

24. Esteller M (2005). DNA methylation and cancer therapy: new developments and expectations. Curr Opin Oncol 17(1): 55-60.

25. Berdasco M \&Esteller M (2010). Aberrant epigenetic landscape in cancer: how cellular identity goes awry. Dev Cell 19(5): 698-711.

26. Cedar H \& Bergman Y (2009). Linking DNA methylation and histone modification: patterns and paradigms. Nat Rev Genet 10(5): 295-304.

27. Guan H, Xie L, Leithäuser F, Flossbach L, Möller P, Wirth T \& Ushmorov A (2010). KLF4 is a tumor suppressor in Bcell non-Hodgkin lymphoma and in classic Hodgkin lymphoma. Blood 116(9): 1469-1478.

28. Zainuddin N, Kanduri M, Berglund M, Lindell M, Amini R M, Roos G \& Rosenquist R (2011). Quantitative evaluation of p16INK4a promoter methylation using pyrosequencing in denovo diffuse large B-cell lymphoma. 28 Leuk Res 35(4): 438-443.

29. Esteller M (2007). Cancer epigenomics: DNA methylomes and histonemodification maps. Nat Rev Genet 8(4): 286.

30. Herranz M \&Esteller M (2007). DNA methylation and histone modifications in patients with cancer. In TargDiscov Valid Rev Prot: Humana Press, pp 25-62.

31. Wang GG Allis CD \& Chi P (2007). Chromatin remodeling and cancer, Part I: Covalent histone modifications. Trends in Mol Med 13(9): 363-372.

32. Glozak MA, Sengupta N, Zhang X \& Seto E (2005). Acetylation and 
deacetylation of non-histone proteins. Gene 363: 15-23.

33. Davis PK \& Brachmann RK (2003). Chromatin remodeling and cancer. Cancer Biol Ther 2(1): 23-30.

34. Bedford DC, Kasper LH, Fukuyama T \& Brindle PK (2010). Target gene context influences the transcriptional requirement for the KAT3 family of CBP and p300 histone acetyltransferases. Epigenetics 5(1): 915.

35. Zhang J, Vlasevska S, Wells VA, Nataraj S, Holmes AB, Duval R \& Hussein S (2017). The CREBBP acetyltransferase is a haploinsufficient tumor suppressor in B-cell lymphoma. Cancer Discov7 (3):322337.

36. Kalkhoven E (2004). CBP and p300: HATs for different occasions. Biochem Pharmacol 68(6): 1145-1155.

37. Squatrito M, Gorrini C \& Amati B (2006). Tip60 in DNA damage response and growth control: many tricks in one HAT. Trends Cell Biol 16(9): 433-442.
38. Calin GA, Dumitru CD, Shimizu M, Bichi R, Zupo S, Noch E \& Rassenti L (2002). Frequent deletions and downregulation of micro-RNA genes miR15 and miR16 at $13 q 14$ in chronic lymphocytic leukemia. Proc Natl Acad Sci 99(24): 15524-15529.

39. Olive V, Bennett MJ, Walker JC, Ma C, Jiang I, Cordon-Cardo C \& He L (2009). miR-19 is a key oncogenic component of mir-17-92. Genes Dev 23(24): 28392849.

40. Kluiver J, Poppema S, de Jong D, Blokzijl T, Harms G, Jacobs S \& Vanden BA (2005). BIC and miR-155 are highly expressed in Hodgkin, primary mediastinal and diffuse large $B$ cell lymphomas. J PatholSci 207(2): 243249.

41. Rothgiesser KM, Fey M \& Hottiger MO (2010). Acetylation of p65 at lysine 314 is important for late NF- $\kappa \mathrm{B}$-dependent gene expression. BMC Genomics 11(1): 22. 